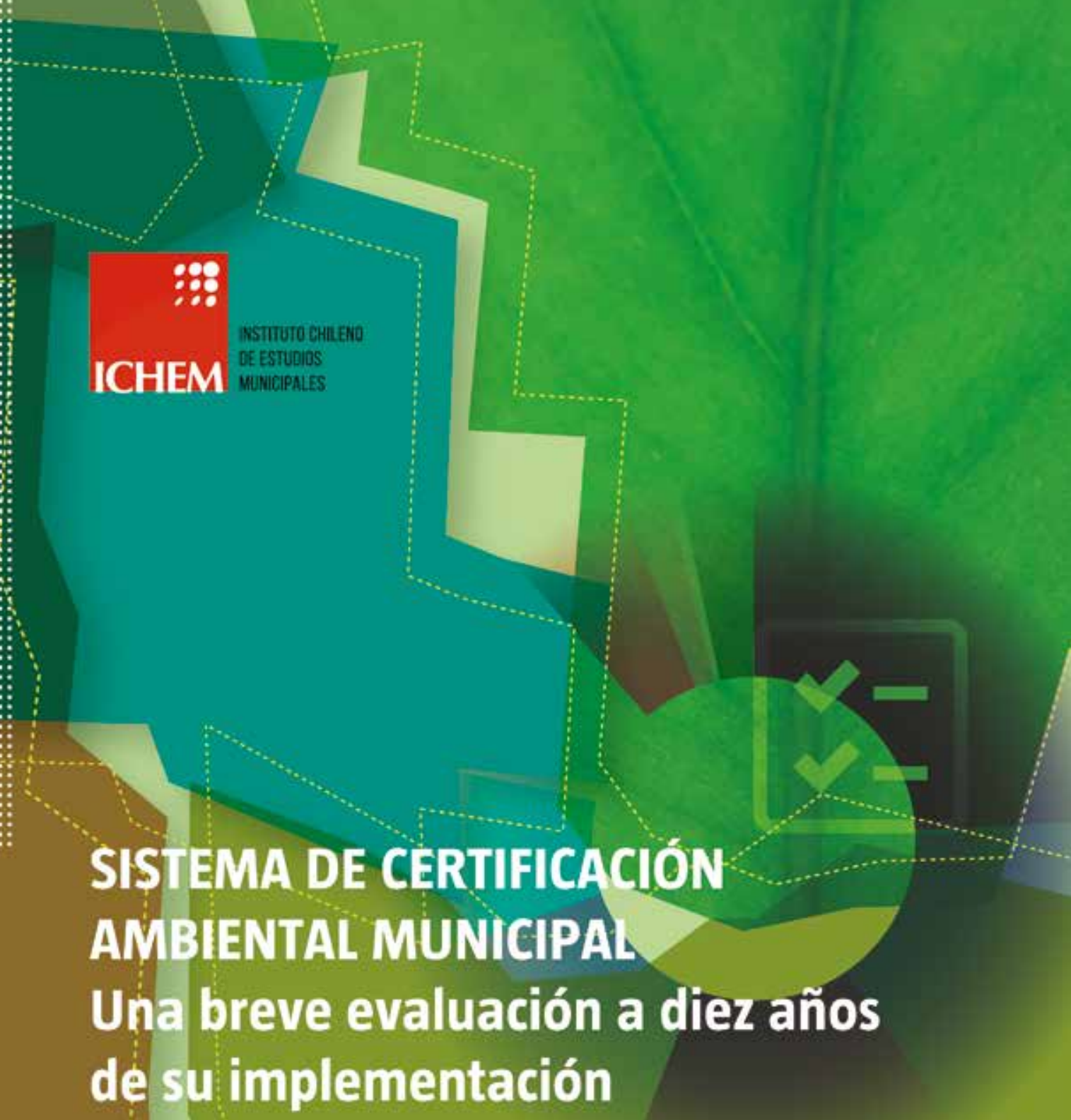




\section{SISTEMA DE CERTIFICACIÓN AMBIENTAL MUNICIPAL. UNA BREVE EVALUACIÓN A DIEZ AÑOS DE SU IMPLEMENTACIÓN Dr. Carlos Rungruangsakorn L.}

Primera edición: enero, 2020.

\section{(c) Universidad Autónoma de Chile}

Centro de Comunicación de las Ciencias

http://ciencias.uautonoma.cl

Santiago, Chile

\section{Instituto Chileno de Estudios Municipales (ICHEM)}

https://ichem.uautonoma.cl

\section{Registro de propiedad intelectual $\mathbf{N}^{\circ} 310840$}

\section{Agradecimientos}

A Marjory Riquelme O., encargada del área de educación ambiental y participación ciudadana de la Seremi de Medio Ambiente de la Región Metropolitana, y a Ítalo Gallardo A., profesional de apoyo para el área de educación ambiental y participación ciudadana de la Seremi de Medio Ambiente de la Región Metropolitana.

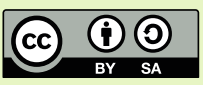

Este material puede ser copiado y redistribuido por cualquier medio o formato, además se puede remezclar, transformar y crear a partir del material siempre y cuando se reconozca adecuadamente la autoría y las contribuciones se difundan bajo la misma licencia del material original.
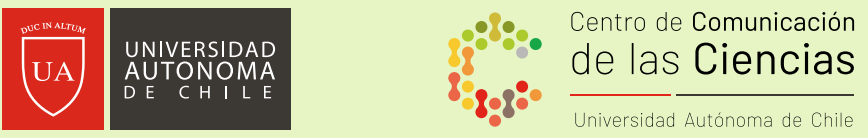

MÁS UNIVERSIDAD 


\section{ÍNDICE}

$>$ ¿Qué es el Sistema

de Certificación Ambiental Municipal (SCAM)?

$>$ ¿Cómo los municipios se incorporan al SCAM?

$>$ ¿Cuál ha sido la evolución del SCAM a nivel nacional y cómo ha sido evaluado?

$>$ Una evaluación cualitativa

$>$ Conclusiones y recomendaciones

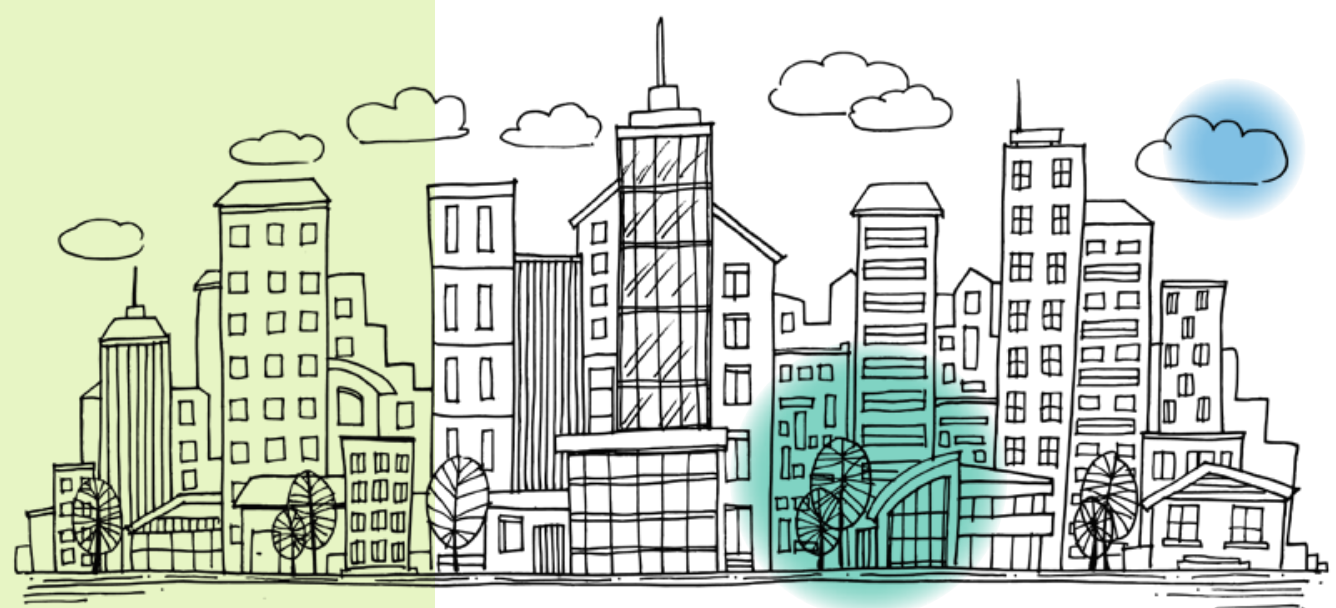

$\varpi \sqsubset \square \square \square \square \square \square \square$ 


\section{PRESENTACIÓN $\rightarrow$}

Hace diez años se implementó el Sistema de Certificación Ambiental Municipal (SCAM) con el objetivo de entregar apoyo técnico y jurídico a los municipios para que estos desarrollaran su potencial de gestión ambiental en concordancia con su realidad territorial, promovieran mejores condiciones ambientales y elevaran así la calidad de vida de sus habitantes conforme a sus valores socioambientales.

En 2009, el SCAM se implementó de manera piloto en tres comunas. Desde entonces la participación ha crecido exponencialmente y, para 2019, de un universo de 345 municipalidades, hay 246 municipios integrados al sistema, es decir, un $71 \%$ del país (Ministerio del Medio Ambiente, 2019). El SCAM se ha convertido, incluso, en un producto de exportación no tradicional y ya ha sido adoptado por Paraguay y Honduras (Fondo Chile, 2019).
En el marco de lo anterior y reconociendo la importancia que ha adquirido la temática ambiental a escala municipal, el Instituto Chileno de Estudios Municipales (ICHEM) de la Universidad Autónoma de Chile ha desarrollado un breve estudio que da a conocer el SCAM a través de la revisión de sus impactos cuantitativos y cualitativos desde su creación hasta hoy.

Esperamos que este documento ayude al proceso de fortalecimiento y transformación de las capacidades municipales y territoriales para enfrentar los desafíos ambientales y climáticos actuales y futuros.

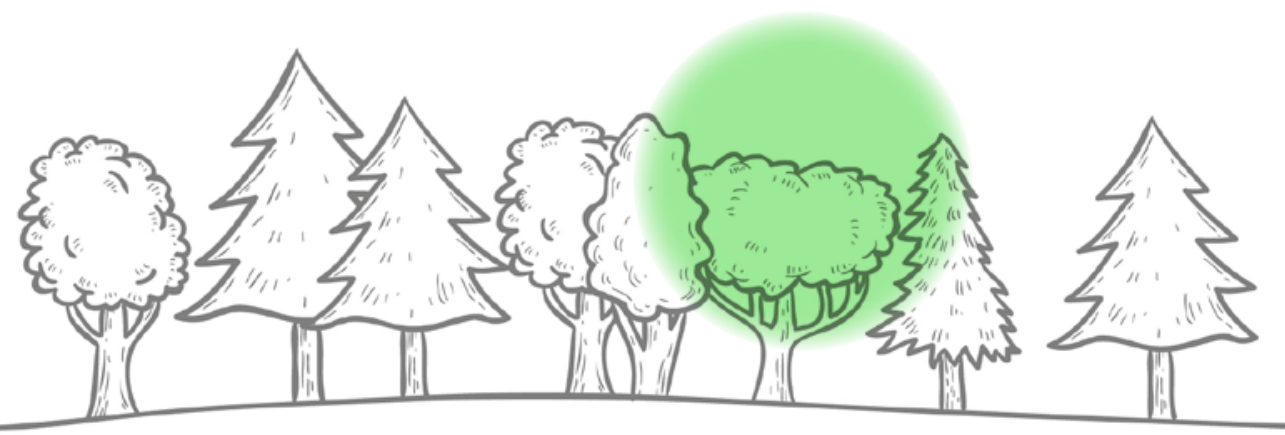




\section{¿QUÉ ES EL SISTEMA}

DE CERTIFICACIÓN AMBIENTAL MUNICIPAL (SCAM)?

El SCAM es un programa desarrollado por el Ministerio del Medio Ambiente para que, voluntariamente, los municipios chilenos integren en su gestión diaria el «factor ambiental» de modo de instalarse en el territorio como un modelo de gestión ambiental donde la orgánica municipal, la infraestructura, el personal, el funcionamiento interno y los servicios que presta el municipio a la comunidad se compenetren con la sustentabilidad ambiental.
El SCAM se concibe como un instrumento que posee una doble funcionalidad, por un lado, permite consolidar o reforzar la gestión ambiental en el municipio, y por otro, inserta en el municipio la configuración básica necesaria para una profundización, evolución y refinación de la gestión ambiental local con el objetivo de que avance hacia un sistema más complejo como la gobernanza ambiental-climática.

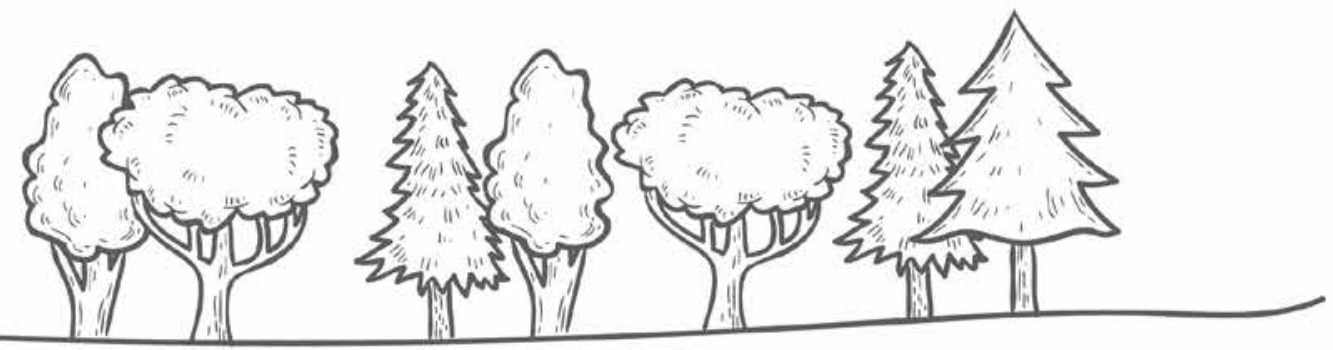




\section{Ty

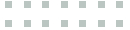

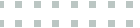

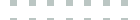

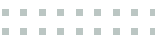

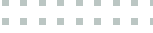

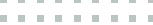 2 \\ ¿CÓMO LOS MUNICIPIOS SE INCORPORAN AL SCAM?}

Los municipios que se adscriben al proceso deben cumplir un ciclo de siete años donde pasan progresivamente por distintas fases: básica, intermedia, excelencia, excelencia sobresaliente y gobernanza ambiental-climática. Sin embargo, desde otra perspectiva, el ciclo también se puede dividir en dos grandes etapas: fortalecimiento ambiental institucional y fortalecimiento de la gestión ambiental territorial y climática.

El fortalecimiento ambiental institucional corresponde a los dos años y medio (fase básica, intermedia y de excelencia) y se caracteriza por el desarrollo de un diagnóstico que es la base para el cumplimiento de una serie de acciones y metas como la elaboración y puesta en marcha de la estrategia y sus lineamientos específicos, la constitución y el funcionamiento de una instancia de participación del comité ambiental comunal y el comité ambiental municipal, desarrollo de capacitación, fomento de educación ambiental, creación de una ordenanza ambiental comunal, entre otros.
La etapa de fortalecimiento de la gestión ambiental territorial climática comprende cuatro años y medio (fase de excelencia sobresaliente y gobernanza ambiental-climática) e implica la revisión y reformulación de la estrategia ambiental, la elaboración de una política ambiental, el desarrollo de planes y proyectos con contenidos ambientales, la consolidación de los comités ambientales, el desarrollo de un plan de fiscalización ambiental activa, de una vocación ambiental comunal participativa y de una mesa público-privada, la cuantificación de la huella de carbono municipal, el plan de riesgos ambientales, los indicadores de protección del patrimonio ambiental de la comuna, entre otros.

Como se observa, las etapas han sido diseñadas de forma sucesiva con la finalidad de que cada una genere las condiciones de cumplimiento de la siguiente. Cabe destacar que las fases otorgan el plazo suficiente para introducir paulatinamente el factor ambiental en el funcionamiento municipal y en sus actividades externas. 


\section{¿CUÁL HA SIDO LA EVOLUCIÓN} DEL SCAM A NIVEL NACIONAL Y CÓMO HA SIDO EVALUADO?

En términos cuantitativos, a la fecha, son 246 municipios los que se encuentran en el sistema y han evolucionado de la siguiente forma:

Participación de los municipios en el SCAM

— Municipios en el SCAM por año

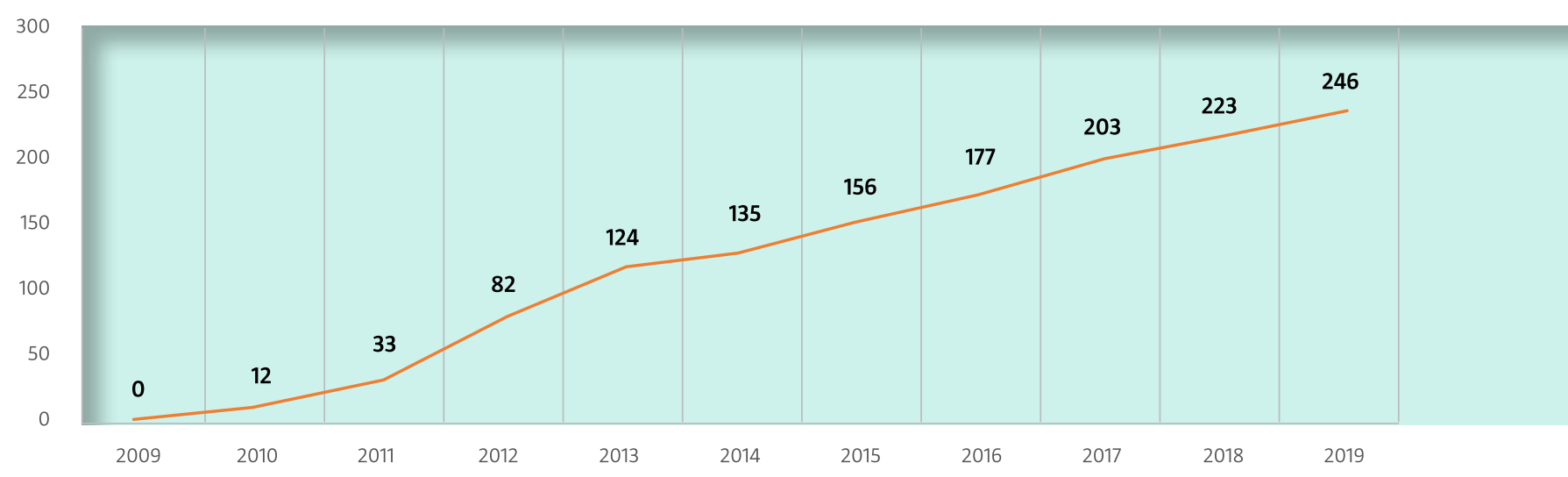


La distribución de los municipios según nivel de certi-

ficación alcanza las siguientes cifras:

Distribución de municipios insertos en el SCAM a 2019

Cantidad de municipios

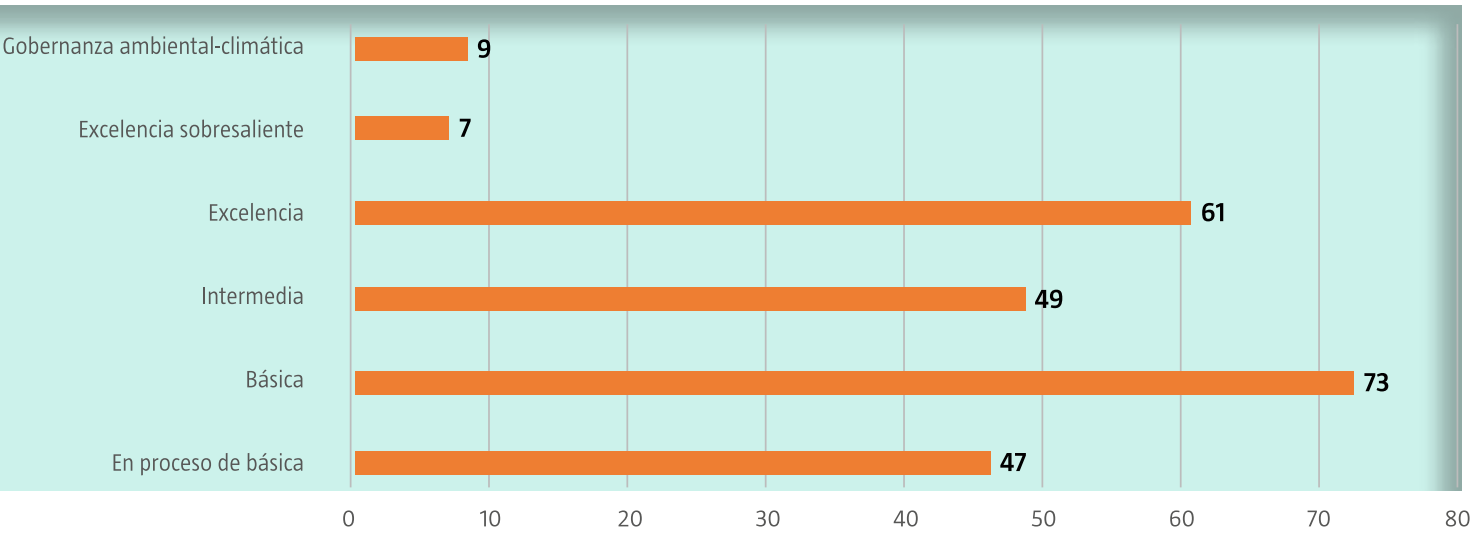

Fuente: elaboración propia a partir de información provista por el MMA

En 2019, el Ministerio del Medio Ambiente realizó una encuesta de calidad cuyo fin era evaluar a los/as encargados/as ambientales municipales. El $75 \%$ del universo de los encuestados respondió el cuestionario. El estudio constó de 19 preguntas, entre ellas, ¿con qué nota evaluaría el programa SCAM? El resultado fue un promedio de 5,75. 
Calificación obtenida por región y a nivel nacional Ranking de notas de evaluación del programa SCAM

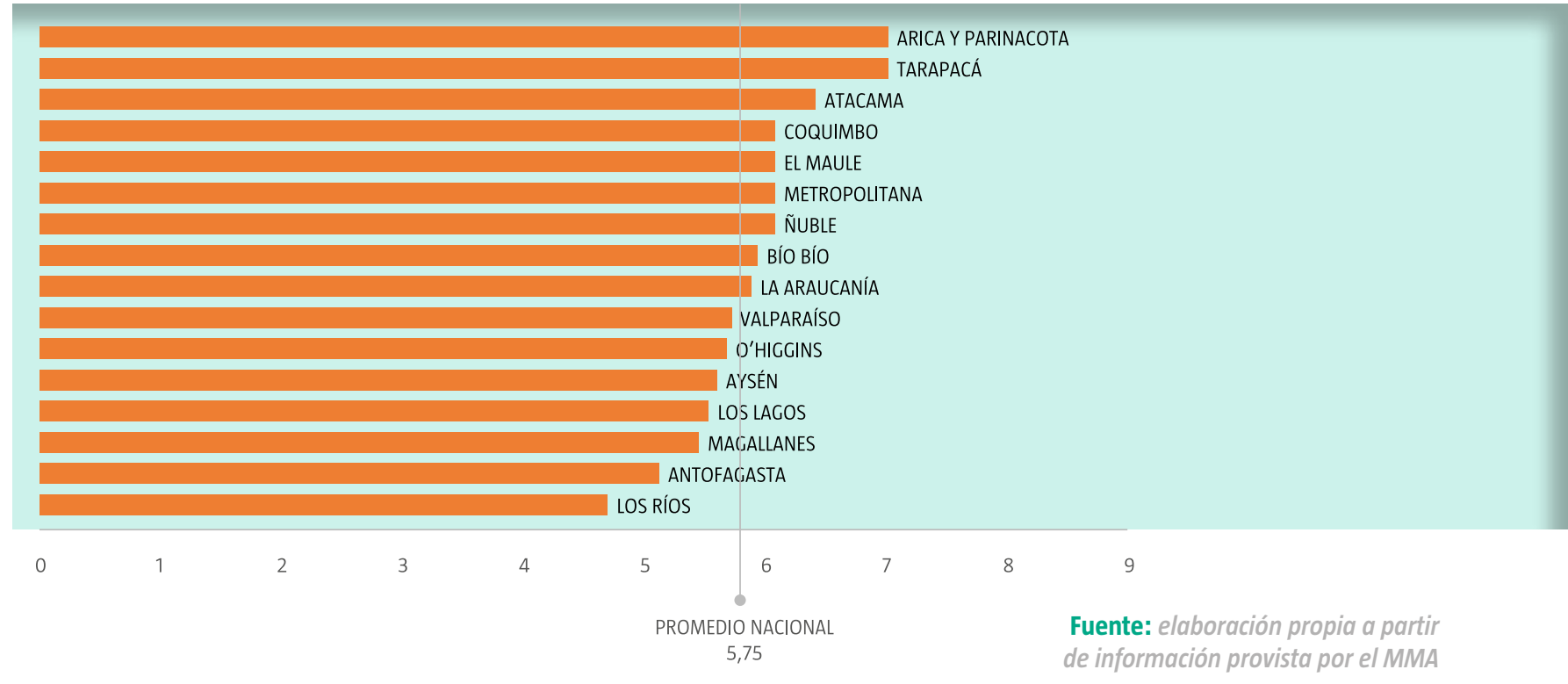

De los datos se desprende que, aun siendo un programa voluntario, el SCAM presenta un crecimiento permanente y los temas ambientales son cada vez más demandados por los municipios. Esto último se corrobora a la luz de los resultados obtenidos por la $\mathrm{VI}$ Encuesta de Actitudes hacia el Medio Ambiente (Universidad Andrés Bello, 2017), donde los municipios aparecen como la segunda entidad que más protege el medio ambiente después del propio Ministerio.
Por otro lado, es interesante observar que el programa, a pesar de tener diez años de existencia, tenga una calificación promedio de 5,75, un valor muy positivo si se considera que las políticas públicas normalmente no son bien evaluadas. Este aspecto es coincidente con las Evaluaciones del desempeño ambiental: Chile 2016 realizado por la Organización para la Cooperación y el Desarrollo Económicos (OCDE), que reconocen al SCAM como un importante mecanismo de fortalecimiento de las capacidades de los municipios, asimilándose a las prácticas vigentes en algunas ciudades de Francia y Suecia (2016: 28 y 114). 


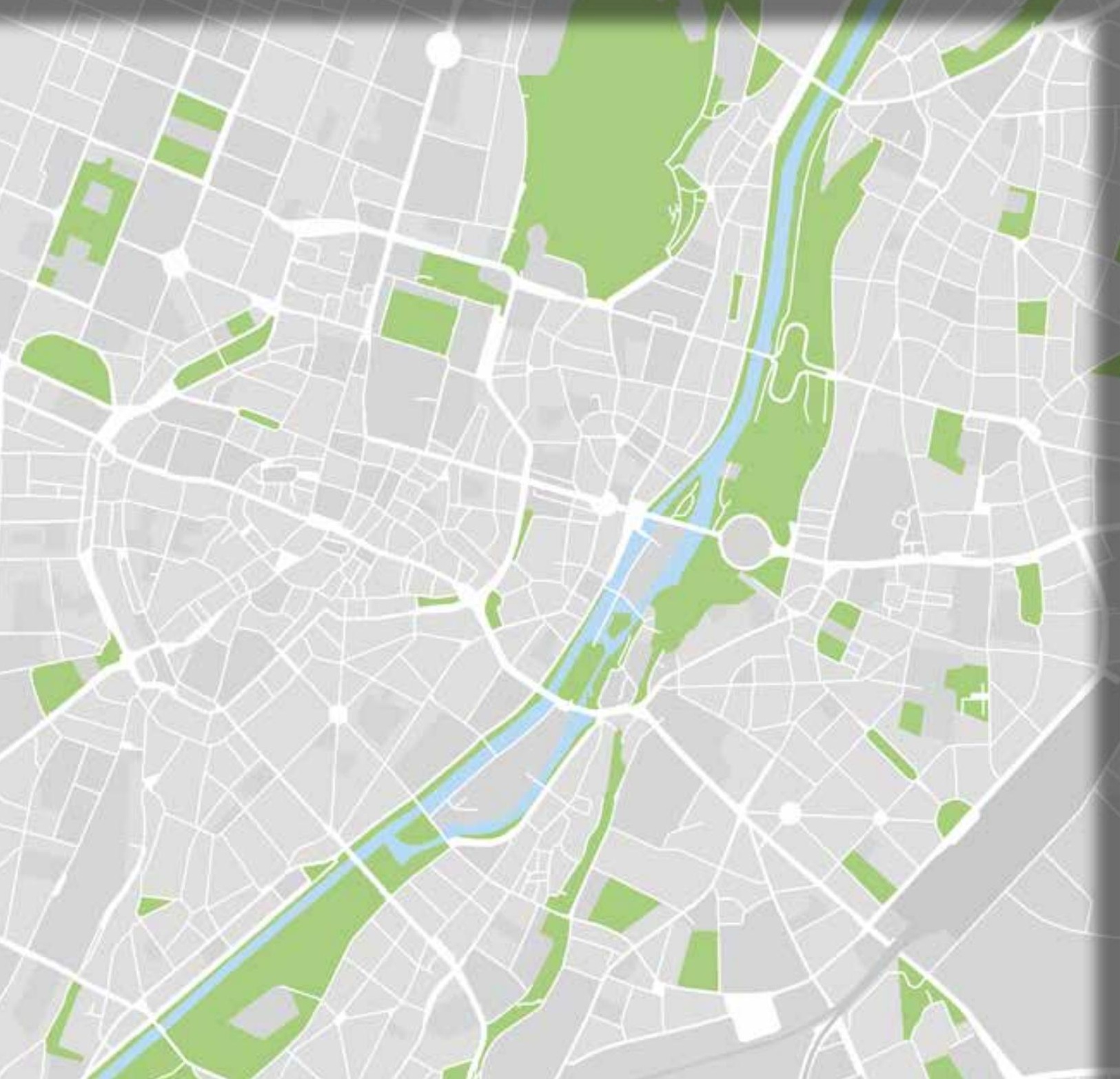




\section{UNA EVALUACIÓN CUALITATIVA}

El Instituto Chileno de Estudios Municipales (ICHEM), en conjunto con la escuela de Administración Pública de la Universidad Autónoma de Chile, desarrolló un estudio cualitativo cuyo fin fue analizar en profundidad los impactos de este instrumento de fomento a la gestión ambiental local. La pretensión del estudio era responder preguntas como ¿qué cambios reales ejerce el SCAM en los municipios? O si existe transformación en la institucionalidad municipal. Para ello, en colaboración con la Seremi de Medio Ambiente de la Región Metropolitana, de los 52 municipios que se encuentran actualmente en el proceso de certificación ambiental, se escogieron ocho casos para estudiar. La selección se basó en los siguientes criterios de inclusión:

a) municipios en la fase tres de la certificación ambiental (excelencia);

b) municipios con el máximo puntaje de certificación (100\%);

c) municipios cuyos resultados de auditorías in situ presenten una alta evaluación.

En este marco, se eligieron las siguientes entidades edilicias: Recoleta, Lo Barnechea, Maipú, Santiago, Quilicura, La Florida, Independencia y Puente Alto.

Si bien el SCAM exige trabajar con quince componentes $^{1}$ en el ciclo de fortalecimiento ambiental institucional, para efectos del presente estudio se abordaron solo cinco de estos factores dado que sus características intrínsecas otorgan indicios explícitos de los avances logrados por el municipio. Las variables seleccionadas fueron:

> ordenanza ambiental;

$>$ estrategia ambiental;

$>$ unidad ambiental;

$>$ presupuesto ambiental; e

$>$ información ambiental.

Cada una se analizó en dos temporalidades diferentes: antes del ingreso al SCAM y posterior al hito de obtención del nivel de excelencia de cada uno de los municipios estudiados. El método comparativo permitió tener un parámetro de los avances alcanzados por los municipios, esto sobre la base de los informes finales de las auditorías realizadas por la Seremi del Ministerio del Medio Ambiente de la Región Metropolitana.

1 Los componentes evaluados en fase 1, 2 y 3: comité ambiental comunal; comité ambiental municipal; ordenanza ambiental; recursos financieros; recursos humanos; tecnología de la información ambiental; tres R; unidad ambiental, participación ciudadana; recursos de planificación ambiental comunal; diagnóstico medio natural, diagnóstico medio construido, diagnóstico socioambiental; estrategia y líneas estratégicas; y compromisos complementarios. 
Resumen analítico del efecto del SCAM en ocho municipios de la Región Metropolitana

\begin{tabular}{|c|c|c|c|c|}
\hline VARIABLE & ORDENANZ & AMBIENTAL & UNID & MBIENTAL \\
\hline Municipalidad & Antes del SCAM & En el SCAM & Antes del SCAM & En el SCAM \\
\hline Independencia & Sin ordenanza. & $\begin{array}{l}\text { Desarrolla y aprueba } \\
\text { ordenanza ambiental } \\
\text { general. }\end{array}$ & Encargado ambiental. & Departamento. \\
\hline La Florida & $\begin{array}{l}\text { Varias ordenanzas con } \\
\text { articulado ambiental. }\end{array}$ & $\begin{array}{l}\text { Desarrolla y aprueba } \\
\text { ordenanza ambiental } \\
\text { general. }\end{array}$ & Oficina. & Departamento. \\
\hline Lo Barnechea & $\begin{array}{l}\text { Varias ordenanzas con } \\
\text { articulado ambiental. }\end{array}$ & $\begin{array}{l}\text { Desarrolla y aprueba } \\
\text { ordenanza ambiental } \\
\text { general. }\end{array}$ & Departamento. & $\begin{array}{l}\text { Departamento } \\
\text { (+ dotación). }\end{array}$ \\
\hline Maipú & $\begin{array}{l}\text { Con ordenanza ambiental } \\
\text { general. }\end{array}$ & $\begin{array}{l}\text { Actualiza ordenanza } \\
\text { ambiental general. }\end{array}$ & Subdepartamento. & $\begin{array}{l}\text { Subdirección } \\
\text { (+ dotación). }\end{array}$ \\
\hline Puente Alto & $\begin{array}{l}\text { Varias ordenanzas con } \\
\text { contenido ambiental. }\end{array}$ & $\begin{array}{l}\text { Desarrolla y aprueba } \\
\text { ordenanza ambiental } \\
\text { general. }\end{array}$ & Departamento. & $\begin{array}{l}\text { Departamento } \\
\text { (+ dotación). }\end{array}$ \\
\hline Quilicura & Ordenanza no actualizada. & $\begin{array}{l}\text { Actualiza ordenanza } \\
\text { ambiental general. }\end{array}$ & Sin datos concluyentes. & Departamento. \\
\hline Recoleta & $\begin{array}{l}\text { Anteproyecto de } \\
\text { ordenanza. }\end{array}$ & $\begin{array}{l}\text { Desarrolla y aprueba } \\
\text { ordenanza ambiental } \\
\text { general. }\end{array}$ & Departamento. & $\begin{array}{l}\text { Departamento } \\
\text { (+ dotación). }\end{array}$ \\
\hline Santiago & $\begin{array}{l}\text { Varias ordenanzas con } \\
\text { contenido ambiental. }\end{array}$ & $\begin{array}{l}\text { Desarrolla catálogo de } \\
\text { ordenanzas ambientales. }\end{array}$ & Gerencia. & Subdirección. \\
\hline
\end{tabular}




\begin{tabular}{|c|c|c|c|c|c|}
\hline \multicolumn{2}{|c|}{ LÍNEA DE ESTRATEGIA COMUNAL } & \multicolumn{2}{|c|}{ PRESUPUESTO AMBIENTAL } & \multicolumn{2}{|c|}{ INFORMACIÓN AMBIENTAL WEB } \\
\hline Antes del SCAM & En el SCAM & Antes del SCAM & En el SCAM & Antes del SCAM & En el SCAM \\
\hline $\begin{array}{l}\text { Proyectos y actividades } \\
\text { ambientales. }\end{array}$ & $\begin{array}{l}\text { Optimización en la } \\
\text { gestión de residuos; } \\
\text { higiene ambiental; } \\
\text { control de las fuentes de } \\
\text { contaminación. }\end{array}$ & $\begin{array}{l}\text { Financiamiento por } \\
\text { medio de proyectos. }\end{array}$ & Sin datos concluyentes. & $\begin{array}{l}\text { Noticias ambientales } \\
\text { ocasionales. }\end{array}$ & $\begin{array}{l}\text { Contenido ambiental } \\
\text { desactualizado. }\end{array}$ \\
\hline $\begin{array}{l}\text { Proyectos y actividades } \\
\text { ambientales. }\end{array}$ & $\begin{array}{l}\text { Residuos inorgánicos; } \\
\text { disminuir los } \\
\text { microbasurales; } \\
\text { participación ciudadana; } \\
\text { tenencia de mascotas; y } \\
\text { educación ambiental. }\end{array}$ & Sin datos concluyentes. & Sin datos concluyentes. & Sin contenido. & $\begin{array}{l}\text { Contenido ambiental } \\
\text { actualizado. }\end{array}$ \\
\hline $\begin{array}{l}\text { Proyectos y actividades } \\
\text { ambientales. }\end{array}$ & $\begin{array}{l}\text { Preservación de la } \\
\text { naturaleza; educación } \\
\text { ambiental; de gestión } \\
\text { integral de residuos; } \\
\text { riesgo por remoción en } \\
\text { masa. }\end{array}$ & Sin presupuesto. & Con presupuesto propio. & $\begin{array}{l}\text { Noticias ambientales } \\
\text { ocasionales. }\end{array}$ & $\begin{array}{l}\text { Contenido ambiental } \\
\text { desactualizado. }\end{array}$ \\
\hline $\begin{array}{l}\text { Proyectos y actividades } \\
\text { ambientales. }\end{array}$ & $\begin{array}{l}\text { Fomento conciencia } \\
\text { ambiental; talleres de } \\
\text { capacitación; tenencia } \\
\text { de mascotas; gestión de } \\
\text { RSD; ecobarrios. }\end{array}$ & Con presupuesto propio. & Sin datos concluyentes. & $\begin{array}{l}\text { Noticias ambientales } \\
\text { ocasionales. }\end{array}$ & $\begin{array}{l}\text { Contenido ambiental } \\
\text { desactualizado. }\end{array}$ \\
\hline $\begin{array}{l}\text { Proyectos y actividades } \\
\text { ambientales. }\end{array}$ & $\begin{array}{l}\text { Educación ambiental; } \\
\text { mejora de servicios; } \\
\text { sensibilización de ahorro } \\
\text { de agua, energía y } 3 R \text {. }\end{array}$ & Con presupuesto propio. & $\begin{array}{l}\text { Con presupuesto propio } \\
\text { incrementado. }\end{array}$ & $\begin{array}{l}\text { Noticias ambientales } \\
\text { ocasionales. }\end{array}$ & $\begin{array}{l}\text { Contenido ambiental y } \\
\text { educativo actualizado. }\end{array}$ \\
\hline $\begin{array}{l}\text { Proyectos y actividades } \\
\text { ambientales. }\end{array}$ & $\begin{array}{l}\text { Educación ambiental; } \\
\text { fiscalización ambiental; } \\
\text { microbasurales; y agua, } \\
\text { entre otros. }\end{array}$ & Sin datos concluyentes. & Sin datos concluyentes. & $\begin{array}{l}\text { Sin información } \\
\text { ambiental. }\end{array}$ & $\begin{array}{l}\text { Contenido ambiental } \\
\text { solo estrategia. }\end{array}$ \\
\hline $\begin{array}{l}\text { Proyectos y actividades } \\
\text { ambientales. }\end{array}$ & $\begin{array}{l}\text { Educación ambiental; } \\
\text { participación ciudadana; } \\
\text { reciclaje comunal. }\end{array}$ & Sin datos concluyentes. & Sin datos concluyentes. & $\begin{array}{l}\text { Sin información } \\
\text { ambiental. }\end{array}$ & $\begin{array}{l}\text { Sin información } \\
\text { ambiental. }\end{array}$ \\
\hline Programas ambientales. & $\begin{array}{l}\text { Conciencia y cultura } \\
\text { ambiental; fortalecer } \\
\text { la institucionalidad; } \\
\text { participación; mejora } \\
\text { de los servicios } \\
\text { ambientales. }\end{array}$ & Con presupuesto propio. & $\begin{array}{l}\text { Con presupuesto propio } \\
\text { incrementado. }\end{array}$ & $\begin{array}{l}\text { Información ambiental } \\
\text { escasa. }\end{array}$ & $\begin{array}{l}\text { Contenido ambiental } \\
\text { desactualizado. }\end{array}$ \\
\hline
\end{tabular}




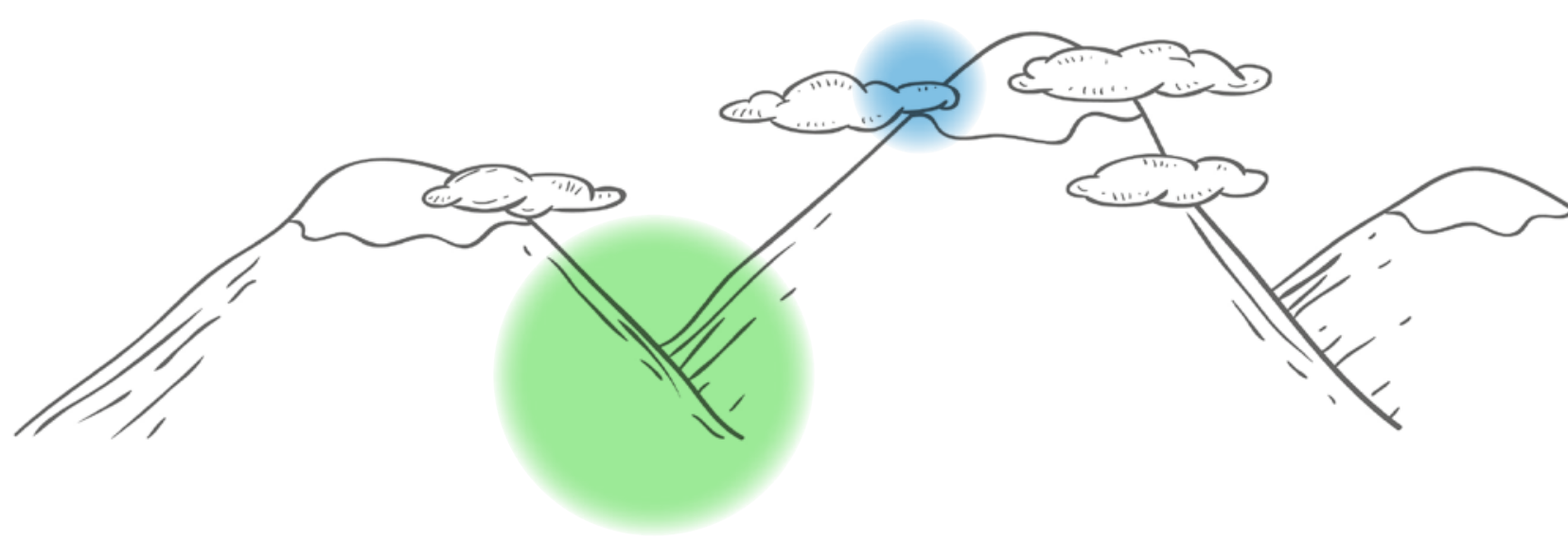

En la tabla se observa que, en general, se presentan efectos positivos del SCAM en la gestión ambiental de los municipios en estudio. De acuerdo con el análisis realizado sobre los informes finales de las auditorías documentales, se evidencia que hay transformaciones reales, especialmente en el desarrollo de la ordenanza ambiental comunal, las unidades ambientales -que alcanzan una mayor jerarquía o logran aumento de personal- y el desarrollo de líneas estratégicas según su realidad local. 


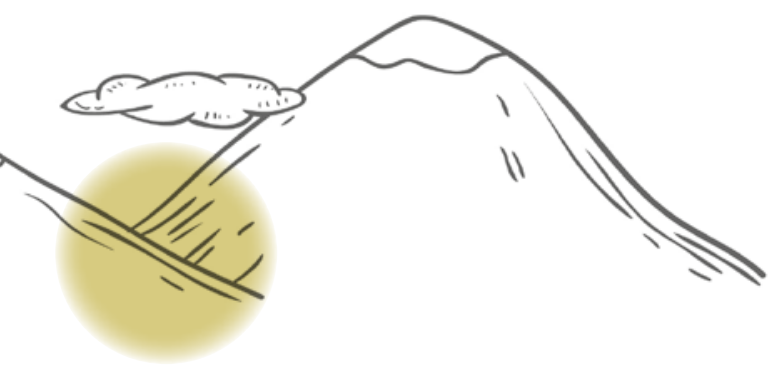

Los puntos más negativos se encuentran, por un lado, en el presupuesto ambiental municipal que presenta antecedentes insuficientes, que no permiten determinar si hubo aumento o no (salvo en dos casos) lo que podría implicar un bajo respaldo financiero a las temáticas ambientales $y$, por otro lado, si bien hay avance en cuanto a la información ambiental municipal disponible en la web, en la mayoría de los casos está desactualizada o sin mantención, lo que impide el desarrollo de una adecuada transparencia pasiva entendida como el mecanismo mediante el cual el aparato público facilita a las personas el acceso a la información pública (Ley N. ${ }^{\circ}$ 20.285).

Para complementar el análisis cualitativo se realizaron seis entrevistas en profundidad, de carácter semiestructurada, a los/as encargados/as municipales de las entidades edilicias en estudio. En cuanto a lo positivo, los entrevistados indican que es un instrumento que ayuda en la planificación ambiental, ordena la gestión y potencia a las unidades ambientales:
El resultado tangible es que por lo menos ya está identificado, desde la parte orgánica del municipio, que hay una unidad ambiental, que no es propiamente tal el Departamento de Gestión Ambiental, sino la Dirección de Medio Ambiente, pero que esta Dirección tiene una unidad ambiental fortalecida donde hoy en día se postula a proyectos, donde se fortalecieron las licitaciones del tema ambiental. $Y$, desde el territorio, el tema de los residuos se ha fortalecido. Los vecinos ya saben que se está postulando a otros puntos limpios donde estamos en constantes talleres.

(Recoleta).

El gran aporte del SCAM es que te sirve para ordenarte, que no se te quede nada afuera [...] Creo que ayuda en la planificación y también hace que el tema medioambiental no quede solo en la unidad de medio ambiente [...] Te obliga a salir de la unidad de medio ambiente y llevar esas temáticas a las diferentes direcciones.

(Maipú). 
Sin perjuicio de lo anterior, los recursos financieros vuelven a ser un tope que no permite un mayor desarrollo de la gestión ambiental local, lo que es corroborado por la $\operatorname{OCDE}(2016,114)$ cuando afirma que los municipios «tienen muy poca autonomía fiscal y carecen de recursos financieros como para implementar sus limitadas responsabilidades por los servicios ambientales».

En relación a los aspectos negativos, las principales críticas radican en el acompañamiento de los procesos por parte del ministerio, su burocratización y el escaso subsidio financiero entregado:

SCAM es demasiado burocrático, mucho papeleo que en ocasiones quita tiempo (horas administrativas o de escritorio) [...] para estar trabajando en terreno o en proyectos más atractivos para la comunidad.

(Quilicura).

Los recursos económicos son pocos [...] para las cosas que nos solicitan en el SCAM [...] se necesita un poquito más.

(Independencia).

Poco apoyo por parte del ministerio. Quizás se debería asesorar al municipio, como un acompañamiento.

(Lo Barnechea).

En suma, se puede advertir que, en términos globales, el SCAM tiende a fortalecer las estructuras municipales en la temática ambiental y así cumplir con el propósito para el que fue creado y los puntos débiles señalados no son estructurales, por ende, podrían ser subsanables en el corto plazo.

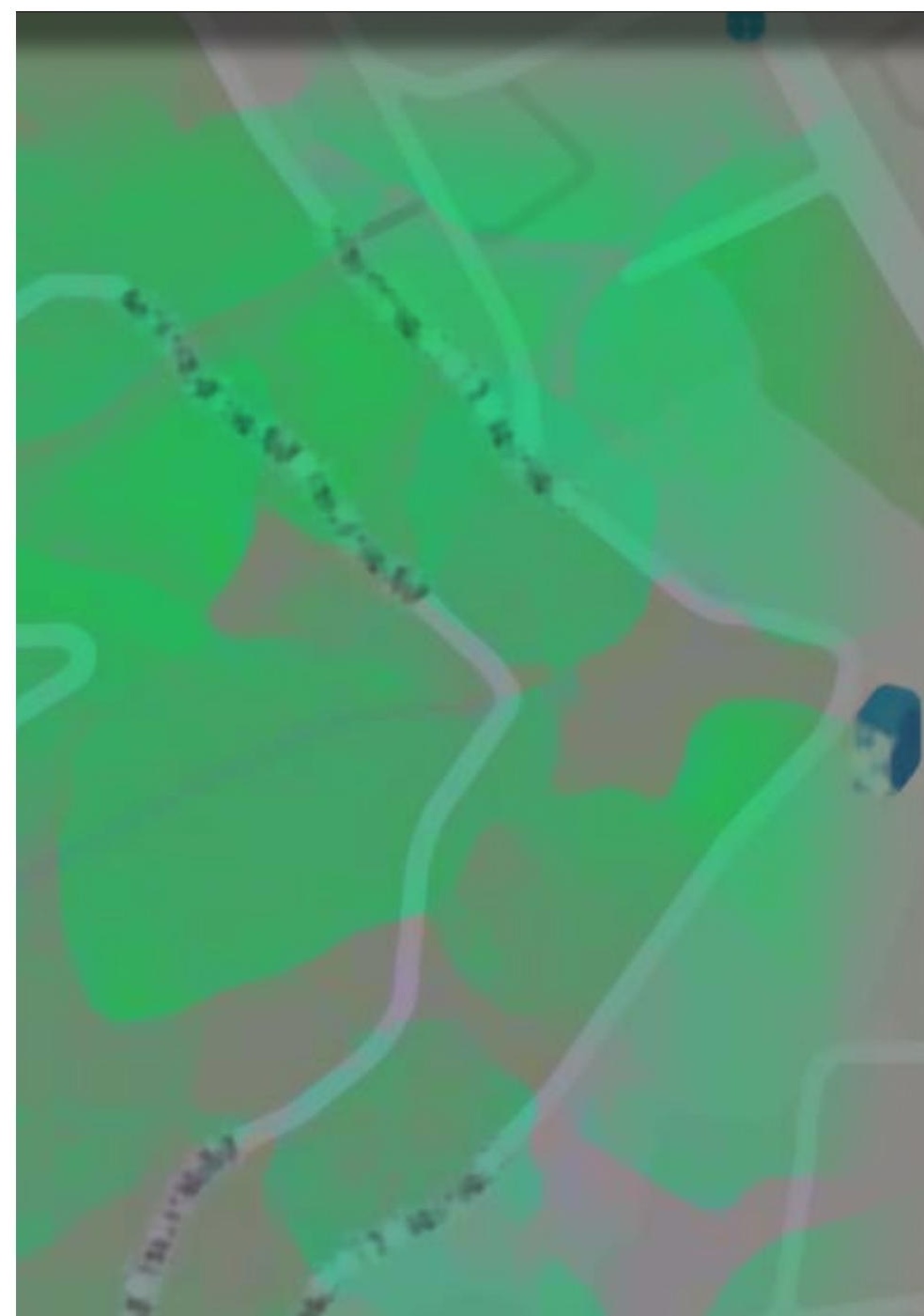




\section{CONCLUSIONES Y RECOMENDACIONES}

EI SCAM no es un sistema aislado y su fortalecimiento va de la mano con transformaciones de las facultades ambientales de los municipios en temas como fiscalización, biodiversidad, multas, planificación ambiental y capacidades adaptativas ante el cambio climático.

La burocracia del SCAM es un aspecto que debe corregirse ya que no solo se advierte en este estudio sino que también fue señalada por el Ministerio del Medio Ambiente $(2016,83)$ cuando anotó que algunos municipios no certificados presentan un "problema administrativo-burocrático, que demanda tiempo, dinero y energía». Por ello se sugiere que el SCAM desarrolle una plataforma digital que permita facilitar los procesos de reportes, auditorías y la transparencia en el acceso a la información. Asimismo, se recomienda una revisión de los medios de prueba a fin de disminuir los aspectos burocráticos que el sistema ha generado durante el tiempo, además de fortalecer el apoyo técnico por parte del ministerio.

En línea con lo anterior, sería deseable que el SCAM generara un modelo o versión simplificada para aquellos municipios más aislados y precarios de modo que el factor burocrático no impida su integración al sistema. 


\section{REFERENCIAS}

> Fondo Chile (2018). Certificación ambiental para gestión municipal y educacional.

Disponible en https://bit.ly/35PE40f

$>$ Ministerio del Medio Ambiente (2019).

Informe encuesta de calidad sobre el Sistema de Certificación Ambiental Municipal.

Chile: Ministerio del Medio Ambiente.

$>---$ (2016). Manual de Certificación Ambiental Municipal.

Chile: Ministerio del Medio Ambiente.

Disponible en https://bit.ly/2L3ECYU

> -- - (2016). Gestión e información ambiental local: diagnóstico y desafíos.

Chile: Ministerio del Medio Ambiente.

> Organización para la Cooperación y el Desarrollo Económicos, OCDE (2016).

Evaluaciones del desempeño ambiental.

Chile: CEPAL. Disponible en https://bit.ly/20xg4di

> Secretaría Regional Ministerial del Ministerio del Medio Ambiente de la Región Metropolitana (2019). Informes de auditorías documentales de Recoleta, Lo Barnechea, Maipú, Santiago, Quilicura, La Florida, Independencia y Puente Alto.

$>$ Universidad Andrés Bello (2017).

VI Encuesta sobre actitudes hacia el Medioambiente.

Chile. Disponible en https://bit.ly/2DpzlBw 



\section{Carlos Rungruangsakorn L.}

Doctor en Ciencias Sociales, magister en Asentamientos Humanos y Medio Ambiente, administrador público y docente en la Universidad Autónoma de Chile.

\section{COLABORADORES DE LA INVESTIGACIÓN}

Javiera Rojas H., Fernanda Carvajal A., Nicolás Muñoz C. y Francisca Quiroz G., estudiantes de Administración Pública de la Universidad Autónoma de Chile.

\section{¿CÓMO REFERENCIAR?}

Rungruangsakorn C. (2019). Sistema de Certificación Ambiental Municipal. Una breve evaluación a diez años de su implementación. Estudio corto ICHEM N. ${ }^{\circ}$ 4. Santiago de Chile: Universidad Autónoma de Chile. Disponible en: http://ichem.uautonoma.cl/category/publicaciones/

\section{Sobre el Instituto Chileno de Estudios Municipales}

Ante la gran importancia que ha adquirido la descentralización del país, el desarrollo territorial y el rol de la administración municipal y regional, el Instituto Chileno de Estudios Municipales, de la Universidad Autónoma de Chile, asume como misión ser un centro de información, de investigación y proyectos de carácter multi e interdisciplinario dedicado a la descentralización del país, al desarrollo territorial y a la contribución en la gestión, eficiencia y resolución de problemas que a diario enfrentan los gobiernos locales y regionales.

Otros títulos de esta serie:

$>$ Transparencia en las municipalidades. Una mirada a 10 años de la ley 20.285

Descárgalo en: https://bit.ly/2QlLbdw

$>$ Barreras para la organización popular en el Chile democrático. Descárgalo en: https://bit.ly/2M9VIGZ

$\rightarrow$ Políticas y programas de infancias y adolescencias a nivel municipal. Descárgalo en: https://bit.ly/2rzB9uY 